\title{
Spatial interaction between seabirds and prey: review and synthesis
}

\author{
Per Fauchald* \\ Norwegian Institute for Nature Research, Polar Environmental Centre, 9296 Tromsø, Norway
}

\begin{abstract}
The Ideal Free Distribution theory predicts a close spatial match between predators and prey. Studies have shown that seabird and prey distribution seldom conforms with this prediction. In this study, I review recent theoretical advances in spatial predator-prey interactions and relate these with studies of seabirds and pelagic schooling fish and crustaceans. Studies on seabirds and prey have generally assumed that prey are nonresponsive. Predator-prey interactions should, however, be viewed as a 2-way spatial game where seabirds track concentrations of prey while prey move away from areas with high risk of predation. The outcome of the game depends on how seabirds and prey are spatially constrained. Constraints include the spatial distribution of resources, interspecific competition, the location of spawning and breeding areas, and limitations on diving depth. Although game theoretic models can explain some general aspects of the spatial interaction, the spatial distribution of seabirds and prey is generally much more aggregated and elusive than can be expected from the game theoretic equilibrium. This is because spatial pattern is formed through selforganizing behavior that includes schooling, local enhancement and area-restricted search (ARS). Schooling and local enhancement are processes with strong positive density dependence that destabilize the predator-prey interaction locally. However, the unstable local dynamics might be stabilized by spatial constraints and the effects of ARS processes at large scales.
\end{abstract}

KEY WORDS: Game model $\cdot$ Schooling $\cdot$ Local enhancement $\cdot$ Area-restricted search $\cdot$ Euphausia superba $\cdot$ Mallotus villosus $\cdot$ Clupea spp. $\cdot$ Diomedea spp. $\cdot$ Uria spp. $\cdot$ Rissa tridactyla

\section{INTRODUCTION}

The nature of the relationship between the spatial distribution of predators and the spatial distribution of prey affects the foraging success of predators and the mortality rate of prey. To increase their foraging success, predators should seek out areas with high prey density while prey, in order to reduce the risk of mortality, should move away from areas with high density of predators (Sih 1984, 2005). Pelagic seabirds are highly mobile and conspicuous marine predators that forage on small pelagic schooling fish and zooplankton. They can move over long distances at relatively low cost while their prey has a scaledependent patchy-and often elusive - spatial distribution (reviewed by Weimerskirch 2007). The develop- ment of acoustic methodology for measuring the abundance of fish and zooplankton has made it possible to investigate the synoptic spatial distribution of seabirds and their prey along ship transects (see reviews in Hunt 1990, Hunt et al. 1999). Seabirds have a high and constant energy demand, and, combined with their high mobility they can be expected to show a strong aggregative response towards concentrations of prey. However, 30 years of spatial studies of seabirds and prey have yielded highly variable results (see Hunt et al. 1999). Many studies find weak positive or even negative spatial relationships between seabirds and prey (e.g. Woodby 1984, Obst 1985, Safina \& Burger 1985, Heinemann et al. 1989, Veit et al. 1993, Logerwell \& Hargreaves 1996, Swartzman \& Hunt 2000). A few studies report strong positive correlations (e.g. Ryan \& 
Cooper 1989, Erikstad et al. 1990, Piatt 1990, Mehlum et al. 1996). Finally, many studies find that the relationship becomes stronger at increasing measurement scales (e.g. Heinemann et al. 1989, Erikstad et al. 1990, Hunt et al. 1992, Logerwell \& Hargreaves 1996, Fauchald et al. 2000, Skov et al. 2000).

The spatial pattern of seabirds and prey is formed by a number of different environmental, ecological and behavioral factors. Each factor operates within specific spatial and temporal scales. Moreover, the factors are often hierarchically interlinked so that large-scale processes set the condition for processes at smaller scales (Wu \& Loucks 1995). For example, large-scale physical properties of the ocean might set limits to the potential habitat of an organism, while within this habitat, the local distribution might be determined by ecological interactions such as competition or predation. Such hierarchically interlinked processes will produce nested patch mosaic hierarchies where smallscale patches are nested within patches at larger scales (Kotliar \& Wiens 1990, Fauchald et al. 2000). For example, the Antarctic krill Euphausia superba is aggregated within swarms at a scale of 10 s of meters. Swarms are aggregated within patches at a scale of kilometers, and patches are aggregated within concentrations at a scale of 100s of kilometers (Murphy et al. 1988).

A major research task is to unravel the processes that produce the complex spatial pattern of organisms in the marine pelagic ecosystem (e.g. Levin 1992). One such process is the spatial interaction between predator and prey. In this paper, I briefly review recent theoretical advances in the understanding of spatial predator-prey interactions. I argue that the interaction between seabirds and prey should be viewed as a 2-way spatial game where the outcome depends on how the participants are spatially constrained. However, in systems where such constraints are lacking or in systems where prey or predators have an aggregative behavior associated with positive density dependence, highly patchy spatial distribution and elusive relationships can be expected. Schooling, local enhancement and area-restricted search (ARS) are behaviors that will produce elusive and aggregated spatial patterns. I relate these theories with empirical findings within a scale-dependent framework.

\section{THE SPATIAL GAME BETWEEN PREDATOR AND PREY}

Although the spatial matching of predators and prey is the result of a 2-way interaction (Sih 2005), studies have focused on either the predator or the prey side of the behavioral response race (Lima 2002). On the predator side, studies have generally assumed that prey are nonresponsive and have typically addressed optimal foraging and patch use (Stephens \& Krebs 1986). Central to this perspective is the idea of the Ideal Free Distribution (IFD) (Fretwell \& Lucas 1970). This framework assumes that predators act to maximize foraging efficiency, are free to move among habitat patches, have perfect knowledge about the distribution of resources, are equal competitors, and decrease individual resource intake with predator density. The IFD predicts an evolutionary stable strategy where the distribution of predators will match the distribution of resources and all predators will obtain an equal rate of returns (see e.g. Millinski \& Parker 1991). This prediction has been termed the 'habitat matching rule' which predicts a positive spatial relationship between predators and prey.

Contrary to the studies from the predator side of the interaction, studies from the prey perspective have assumed a fixed predation risk and have typically addressed questions such as the trade-off between predation risk and foraging (Abrahams \& Dill 1989, Lima \& Dill 1990). For example, the diurnal vertical migration of zooplankton from the euphotic zone has been viewed as a behavioral response to avoid predation from visual predators, resulting in a trade-off between feeding and predation risk (Iwasa 1982). Recently, it was proposed that alteration of the composition of the predator community may result in fundamental changes in the habitat use of keystone herbivores with subsequent changes in ecosystem properties (e.g. Ripple et al. 2001, Willis 2007).

Combining both predator and prey perspectives in a modeling framework has been a major task in recent years (van Baalen \& Sabelis 1993, Hugie \& Dill 1994, Sih 1998, Alonzo 2002, Fiksen et al. 2005, Abrams 2007). These models investigate the behavioral conflict game where predators aggregate in areas of high prey density, while prey are free to move in order to reduce predation risk. The resources are typically distributed in patches of different quality, prey respond to resources and the risk of predation while predators respond to prey availability (Fig. 1). The models evaluate the existence of an IFD in which both prey and predators have reached an evolutionary stable strategy where the system is stable in the sense that individual predators as well as individual prey have equal fitness in different resource patches and cannot do better by moving. According to a number of different models (reviewed in Sih 2005), predators should aggregate in patches with high input of resources. Prey are also predicted to aggregate in the most productive patches; however, as a consequence of increased predation risk, they should have a more uniform distribution among resource patches (Fig. 1). Thus, these models essentially confirm the habitat matching rule, predicting a 

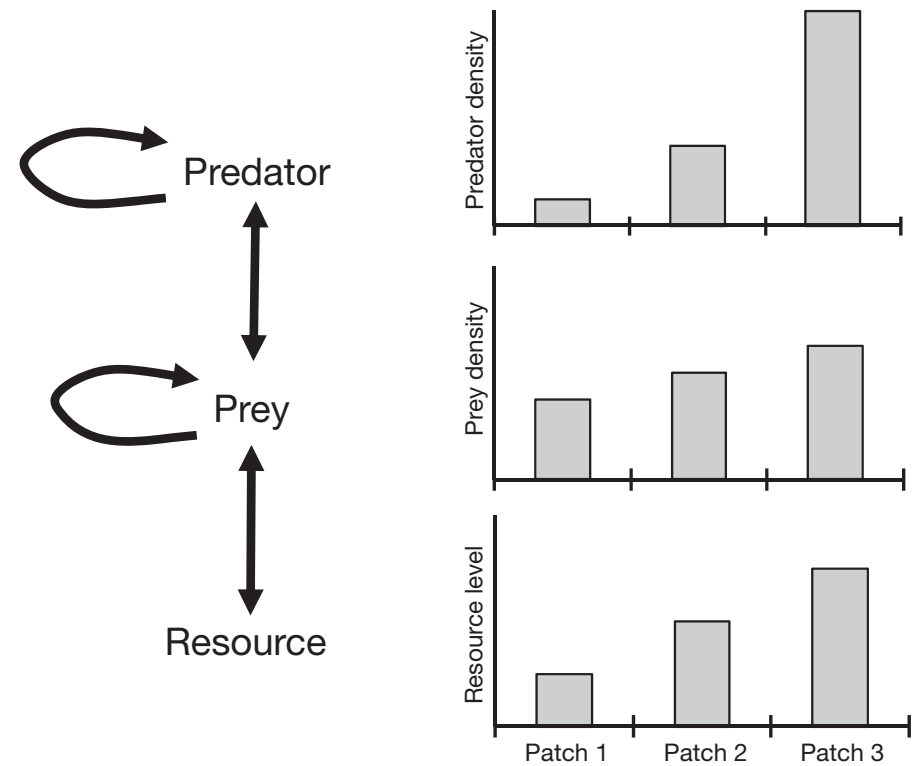

Fig. 1. Behavioral game models of the spatial interaction between predator and prey. Left: general trophic stucture of the models (redrawn from Alonzo 2002). Arrows indicate interactions. Predators and prey distribute themselves within patches with different levels of resources. Prey respond to the resource level and the risk of predation, predators respond to prey density. Predators and prey respond to their own density through competition. They are assumed to obey the Ideal Free Distribution assumptions (individuals have perfect knowledge of patch quality and are free to move among patches). The models evaluate the existence of an evolutionary stable strategy where predators and prey are unable to do better by moving to another patch (the gain is equal among patches). Right: generalization of model predictions as suggested by Sih (2005); both predators and prey should aggregate in the most productive patches. However, due to predation risk, prey should have a more uniform distribution across patches than predators positive relationship between predators and prey. In Sih's (2005) terminology, the predators win the game. He argues that this outcome is due to constraints imposed on prey by the distribution of resources in these models. Because the spatial distribution of resources is fixed, prey is subject to a spatial anchor. If, on the other hand, the predator is subject to a spatial anchor, prey will have a refuge and a negative relationship between predators and prey may be expected. For example, in a model by Alonzo et al. (2003) on the interaction between breeding penguins and krill, penguins were constrained by both the vertical (constraints on diving depth) and horizontal distribution (constraints on travel distance to the breeding colony) of krill. According to this model, krill win the game by distributing themselves offshore and maintaining vertical migration.

In the absence of spatial constraints, conflict games between predators and prey might not have any equilibrium (Schwinning \& Rosenzweig 1990, Sih 2005, Abrams 2007). Indeed, changing some of the assumptions of the models might result in a non-equilibrium spatial distribution. For example, Abrams (2007) introduced satiation in the functional responses of predators and prey in a simple resource-prey-predator model and showed that this model was generally spatially unstable. Predator satiation made predator dilution possible and prey accordingly tended to dilute predation risk by aggregating in patches. However, as a consequence of resource consumption and predator aggregation, it would eventually be optimal for prey to move from an aggregation. Consequently, predators chased aggregations of prey from patch to patch in an unstable and cyclic system (Abrams 2007). In these cases where stable and equal fitness between patches is unachievable, the matching between consumer and resource and between predator and prey should be highly variable.

In summary, theory predicts that spatial constraints will tend to stabilize the spatial distribution of predators and prey (Sih 2005). When prey is constrained by a spatial anchor, the predators will win the race and a positive relationship between predators and prey may be expected. On the other hand, when a spatial constraint is imposed on the predator, prey will win and a negative relationship may be expected. In systems where such constraints are weak and where positive density dependence such as predator dilution is dominant, a highly aggregated and elusive system with no clear pattern of predator and prey matching may be expected (sensu Abrams 2007).

\section{Spatial handicaps of prey}

The spatial distribution of resources may limit the spatial distribution of prey and thus give the predator an advantage in the spatial 'arms race'. Physical processes in the ocean such as currents, fronts, upwelling, vertical mixing and stratification determine the spatial pattern of primary production and are responsible for the transport and concentration of nutrients and plankton (Haury et al. 1978). The result is a complex and scale-dependent spatial pattern in the resources available to krill and small pelagic schooling fish which in turn are prey for seabirds and other top predators (see review in Hunt \& Schneider 1987, Weimerskirch 2007). According to the equilibrium models (see above), seabirds should show a strong affinity to areas characterized by physical properties that enhance or accumulate resources available to their prey. 
Several studies have shown that seabirds tend to aggregate in areas with specific oceanographic properties (see Hunt et al. 1999 for review). Elevated abundance of seabirds is found in areas characterized by high production or accumulation of biological matter, such as in frontal areas delineating different water masses (Abrams 1985, Wahl et al. 1989, Pakhomov \& McQuaid 1996, Hyrenbach et al. 2007), along the continental edge (Hay 1992, Piatt et al. 2006), or in inshore waters (Harrison et al. 1994). On a smaller scale, local interactions between currents and the sea bottom may structure water masses into zones with different properties. For example, the Pribilof Islands in Alaska are surrounded by a structural tidal front defined as the boundary between well-mixed inshore waters and stratified offshore waters (Fig. 2). This frontal area is characterized by elevated stocks of phytoplankton, zooplankton, fish and seabirds (Kinder et al. 1983, Schneider et al. 1990, Coyle \& Cooney 1993, Decker \& Hunt 1996, Hunt et al. 1996). Similarly, in the Irish Sea, Durazo et al. (1998) found elevated concentrations of seabirds associated with a tidal front. In the California Current System, small-scale upwelling events affect prey availability and habitat selection by marbled murrelets Brachyramphus marmoratus (Becker \& Beissinger 2003). Seabirds that prey on meso zooplankton that are more or less passively transported by ocean currents largely rely on physical processes that concentrate the prey in the upper part of the water column. For example, least auklets Aethia pusilla in the northern Bering Sea (Hunt \& Harrison 1990, Hunt et al. 1990) and little auks (Alle alle) in the North Sea (Skov \& Durinck 2000) are found in stratified waters where a shallow pycnocline tends to concentrate copepods close to the surface.

Life history events such as spawning often constrain the spatial distribution of prey to particular areas. For example, the selection of favorable spawning areas by fish might have strong implications for fitness, suggesting strong preference for suitable areas that might be easily predicted and accessed by predators. Studies on auks foraging on small pelagic fish might support this hypothesis. On the eastern shelf of Newfoundland, large breeding colonies of the common murre Uria aalge and Atlantic puffin Fratercula arctica forage on spawning capelin Mallotus villosus (Piatt 1990). Com-
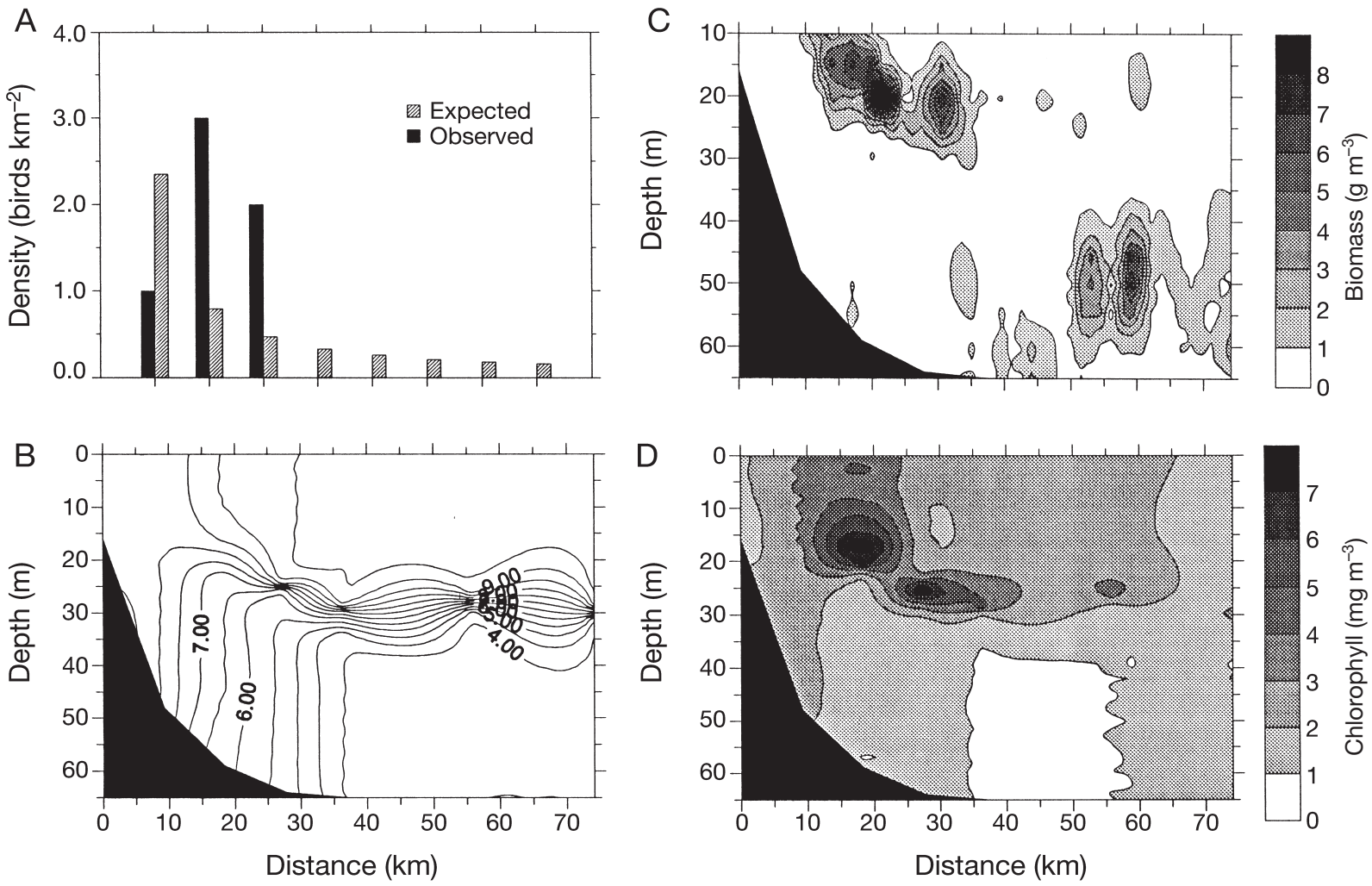

Fig. 2. Aggregation of seabirds, acoustically determined biomass and primary production at a tidal front in the Bering Sea. (A) Expected and observed densities of murres (Uria spp.). Bars represent densities for each $9.3 \mathrm{~km}$ interval along the transect. Expected densities were modeled by a geometric relationship between the distance from the breeding colony and bird density assuming that birds spread out evenly from the colony. (B) Temperature profile $\left({ }^{\circ} \mathrm{C}\right),(\mathrm{C})$ acoustically determined biomass $\left(\mathrm{g} \mathrm{m}^{-3}\right)$ and (D) chlorophyll concentration $\left(\mathrm{mg} \mathrm{m}^{-3}\right)$. Due to tidal currents, a frontal zone is formed between well-mixed inshore waters and stratified offshore waters. The example is from a $74.1 \mathrm{~km}$ long transect radiating out from St. Paul Island (summer 1987).

Figure from Decker \& Hunt (1996), with permission 
mon murres seem to use a combination of memory and local enhancement to keep in contact with reliable patches of spawning capelin that might last for weeks (Davoren et al. 2003). In the Barents Sea, maturing capelin start a spawning migration from the central parts in late winter towards the coast where they spawn in early spring (Gjøsæter 1998). During migration and spawning, capelin is heavily preyed upon by the cod Gadus morhua, seals and seabirds. In a series of studies, Erikstad et al. (1990), Fauchald et al. (2000) and Fauchald \& Erikstad (2002) found strong spatial matching between murres (Uria spp.) and capelin in this period. However, contrary to the spawning situation, the spatial overlap between capelin and murres during the feeding migration of capelin in late summer is weak (Fauchald unpubl. data). This is in accordance with other studies of murres and nonspawning schooling fish that have shown either weak spatial matching (Woodby 1984, Swartzman \& Hunt 2000), matching only on relatively large scales (Skov et al. 2000) or matching that is dependent on oceanographic properties that enhance resource availability to the fish (Cairns \& Schneider 1990, Decker \& Hunt 1996, Logerwell \& Hargreaves 1996).

\section{Spatial handicaps of predators}

When predators are spatially constrained, prey may escape into spatial refuges (see e.g. Rose \& Leggett 1990). One ecological interaction that can impose a spatial constraint is interspecific competition, which can reduce the realized niche of a predator and therefore potentially constrain its habitat use (Chase \& Leibold 2003). Different seabird species have different adaptations and are consequently associated with different parts of the pelagic ecosystem (Abrams 1985, Wahl et al. 1989, Ainley et al. 1992, Harrison et al. 1994, Ballance et al. 1997, Vilchis et al. 2006). For example, in the eastern tropical Pacific, Ballance et al. (1997) identified 3 distinct seabird assemblages associated with areas of different productivity. Small species with low cost of flight, the 'sooty tern flocks', were associated with unproductive waters; intermediate species, the 'Juan-Wedge flocks', were associated with areas of intermediate productivity; and large species with high cost of flight, the 'booby flocks', were associated with areas of high productivity. They suggested that a trade-off between competitive ability (large size) and foraging ability (low cost of flight) was responsible for the niche separation between the different flock types. The spatial constraints imposed by interspecific competition might therefore reduce the possibility of the subdominant species occupying the habitats with the highest availability of prey, con- sequently reducing the spatial match between these predators and their prey at large scales.

During breeding, seabirds are spatially constrained by their duties at the breeding colony. Because seabirds have to return to a central place (i.e. the nest) between foraging bouts, seabirds act as central place foragers in this period (cf. Orians \& Pearson 1979). The feeding area that they exploit is determined by their travel capabilities, the spatial distribution of prey and the frequency by which they return to the nest (see e.g Weimerskirch et al. 1997). A large majority of seabird species ( 96\%) are colonial breeders (Coulson 2002) and the competition for food close to the colony might be strong. Accordingly, it has been suggested that the spatial distribution and size of colonies are determined by both the availability of prey and intraspecific competition (Ashmole 1963). Several recent studies support the hypothesis that competition is an important factor in shaping colony size and distribution: foraging range and trip duration have been found to increase with colony size (Lewis et al. 2001, Ainley et al. 2003), the foraging range of birds from neighboring colonies overlap less than could be expected from the distance between the colonies alone (Ainley et al. 2003, 2004, Grémillet et al. 2004), and the availability of prey around the colony decrease with increasing colony size (Forero et al. 2002, Ainley et al. 2003). From the prey's perspective, the risk of predation decreases with increasing distance from the colony, the colonial breeding of seabirds therefore generating a potential refuge. Lewis et al. (2001) suggested that prey could escape into this refuge by a simple mechanism of diffusion. If prey responds to predator attack by lateral movement, then prey will diffuse out from the colony since the attack rate is highest close to the colony. This diffusion would lead to a slowly growing 'halo' (Ashmole 1963) with reduced density of prey close to the colony (Lewis et al. 2001). Alternatively, prey might respond to attacks by swimming downward, thereby becoming inaccessible to surface-feeding seabirds (see below). In this case, prey availability close to the colony would be less. In Prince William Sound, Alaska, Ainley et al. (2003) found that the prevalence of fish schools close to the surface was inversely related to the colony size of black-legged kittiwakes Rissa tridactyla. They suggested that predator avoidance might be an important density-dependent factor that regulates the number of foraging kittiwakes in this area.

One important factor that constrains the movement of seabirds is the trade-off between movement under and above the sea surface. Seabirds that are adapted for efficient diving have high energy expenditure for flying, and prey may accordingly escape by moving horizontally. Seabirds that are adapted for efficient flying are able to utilize only the upper meter of the 
sea and prey may escape by hiding in the deep. Surface-feeding seabirds are largely dependent on other predators for access to food. Predatory fish, diving seabirds and sea mammals drive schools of prey fish and krill to the surface, making them available to surface-feeding seabirds (Hoffman et al. 1981, Safina \& Burger 1985, Harrison et al. 1991, Mills 1998). Multi-species seabird flocks around South Georgia are, for example, generated when seals and penguins drive krill to the surface (Harrison et al. 1991). Blackbrowed albatrosses Diomedea melanophris initiate and dominate these feeding flocks and act as attractors of other foraging seabirds (Harrison et al. 1991, Grünbaum \& Veit 2003). Because surface-feeding seabirds are able to utilize only a very small proportion of the vertical habitat of their prey, prey may easily escape predation with minimum cost. Surface-feeding birds are therefore likely to have a very small impact on the prey population. On the other hand, diving seabirds could cover a larger proportion of the vertical habitat of their prey. Moreover, because these predators operate in the most productive euphotic zone, their prey are likely to face a trade-off between a risky and productive habitat versus a safe and unproductive habitat (Alonzo et al. 2003). Diurnal vertical migration is a strategy that allows prey to escape visual predators during the day while they may feed in the euphotic zone at night (Iwasa 1982). Alonzo et al. (2003) modeled the spatial interaction between penguins and krill and showed that penguins could possibly have a strong effect on the spatial distribution of krill by forcing them to stay offshore and undertake diurnal vertical migration. Willis (2007) suggested that the large baleen whales in Antarctic waters are highly effective predators on krill below the euphotic zone and that krill as a consequence reduce its vertical migration under high predation pressure from whales. He suggested that this behavioral response was responsible for the 'Antarctic paradox', i.e. that krill abundance has failed to increase after the decimation of baleen whales during the 20th century. Under high density of whales, the ecosystem was much more productive simply because krill was forced to stay in the euphotic zone. After the removal of whales, it became optimal for krill to undertake vertical migration to avoid predation from e.g. seabirds, and the ecosystem consequently became less productive.

\section{SPATIAL PATTERN GENERATED BY SELF- ORGANIZATION}

Within the framework of the IFD theory, it is expected that predators and prey will distribute them- selves freely according to costs and benefits until a stable equilibrium has been achieved. According to this theory, both competition and predation are expected to make the distribution of organisms more uniform across resource patches. However, in marine pelagic ecosystems this is not the case. Spatial complexity generally increases with increasing trophic level (Levin 1992). Thus, the spatial distribution of pelagic schooling fish is more aggregated than that of their resources. In fact, while the IFD theory predicts a more even distribution of competitors due to increased competition under high density (Sutherland 1983), the aggregation of capelin actually increases in years of high abundance when intense competition for resources is expected (Fauchald et al. 2006). Moreover, the spatial distribution of predators and prey is highly elusive (e.g. Fauchald et al. 2000, Becker \& Beissinger 2003, Fauchald \& Tveraa 2006). Predators are not able to stay in contact with patches of prey for long periods of time (Harrison et al. 1991, Grünbaum \& Veit 2003) and large portions of prey patches are at some time not subject to predation (Obst 1985, Heinemann et al. 1989, Swartzman \& Hunt 2000), suggesting that the distribution of predators and prey is generally far from any IFD equilibrium.

The reason for the discrepancy between the IFD predictions and the observed spatial pattern is that seabirds and prey seldom comply with the IFD assumptions. These assumptions are that predators and prey have perfect information about the environment and that they are free to move to any part of the environment with no associated cost. It has long been known that the process of learning where prey patches are can lead to differences between the actual distribution of a predator and that predicted by the IFD (Bernstein et al. 1988). Constraints on information and movement might accordingly be central for the outcome of the spatial game between predators and prey. Furthermore, relaxation of the assumption of omniscient and unrestricted individuals means that individuals must respond to local stimuli in order to maximize their foraging success or minimize the risk of predation. Such local responses include local interactions between individuals such as those between competitors or between predators and prey. When repeated, local interactions between individuals result in what has been termed 'collective selforganizing behavior' that again produces complex and possibly adaptive spatial patterns at a higher level of organization (see review in Sumpter 2006). For example, in the model of Lewis et al. (2001) (see above), the local response of prey to the attacks from seabirds results in a spatial pattern where the density of prey increases with increasing distance from the seabird colony. 


\section{Schooling}

Schooling in fish is a classic example of collective self-organizing behavior (self-organization) where simple interactions between individuals produce a complex spatial unit (Parrish \& Edelstein-Keshet 1999). More than $50 \%$ of all known fish species form schools at some part of their lives (Shaw 1978) and protection from predation has been the main explanation for this behavior (Partridge 1982, Parrish \& Edelstein-Keshet 1999). For an individual facing a predator, it is adaptive to seek protection by keeping close to conspecifics, thereby diluting the risk of attacks (Hamilton 1971). However, a school of fish is a highly valuable entity that attracts predators. Joining a school is therefore adaptive only when the increased protection from dilution is greater than the increased risk of predation due to increased conspicuousness to predators. Low visibility reduces the risk of being detected, and Partridge (1982) suggested that low visibility makes schooling a particularly adaptive anti-predator behavior in the marine pelagic environment. However, whenever predators are able to find and aggregate effectively on concentrations of prey, schooling can be a hazardous strategy. Temming et al. (2007) showed for example how an aggregation of $>50$ million juvenile cod within an area of only $18 \mathrm{~km}^{2}$ was entirely wiped out in $5 \mathrm{~d}$ by predatory whiting Merlangius merlangus. To avoid aggregation of predators, it is therefore essential for the school to move rapidly and unpredictably (see e.g. Mitchell \& Lima 2002). Rapid vertical and horizontal movement makes it difficult for predators to stay in contact with the school for long periods of time and will hinder predators from aggregating on the school. Presumably as a consequence, krill and pelagic schooling fish are highly elusive and patchy resources.

In pelagic schooling fish and krill, anti-predator behavior will often conflict with other types of behavior that enhance fitness components such as growth and reproduction. The observed spatial behavior will therefore be the result of a compromise between survival, growth and reproduction (e.g. Nøttestad et al. 1996, Axelsen et al. 2000, Johnsen \& Skaret 2008). Such trade-offs change markedly between different life stages resulting in changed anti-predator behavior. For example, one marked shift in behavior happens from pre-spawning to spawning to post-spawning in Atlantic herring Clupea harengus (Nøttestad et al. 1996, Axelsen et al. 2000). Prior to spawning, herring should give priority to survival. Accordingly, herring approach the shallow, coastal spawning grounds in dense, nonfeeding, fast and deep swimming schools. In the spawning grounds, spawning takes place on the bottom where the spawners are highly vulnerable to predation. Thus, schools of spawners await in a safe pelagic position, and then at some point, descend to the bottom for spawning. After spawning, survivors should give priority to recovery and growth. Accordingly, post-spawning herring leave the spawning grounds in smaller, less dense feeding schools with a shallow position in the water column. Shifts in the trade-offs that regulate the spatial anti-predator behavior could be reflected by changes in the spatial predator-prey interaction. For example, a small-scale spatial mismatch between seabirds and prey prior to spawning could be expected to turn into a spatial match during and after spawning. However, I am not aware of any studies that explicitly address this question.

\section{Local enhancement}

Seabirds may use a combination of visual and olfactory cues to detect patches of prey (Nevitt et al. 1995, Davoren et al. 2003). However, they may also indirectly locate schools or swarms of prey by observing the foraging behavior of other seabirds (Hoffman et al. 1981, Harrison et al. 1991, Grünbaum \& Veit 2003, Silverman et al. 2004). This strategy has been termed 'local enhancement' and simply assumes that it is much easier for a seabird to detect foraging conspecifics than it is to detect prey patches directly. Accordingly, when seabirds search for prey, they can either detect a patch of prey directly or they can join a flock of other seabirds that has already found a patch. Depending on the asymmetry in the detectability of prey versus other foragers, local enhancement will produce a highly aggregated spatial distribution of predators. Accordingly, intense predation will be concentrated to a few resource patches while many patches will be free from predators. This type of spatial distribution of seabirds and prey has typically been found on small spatial scales when prey consists of pelagic schooling fish or krill (e.g. Obst 1985, Heinemann et al. 1989).

Local enhancement is adaptive only when prey is patchy and elusive; thus, this behavior can be viewed as an adaptive response to schooling. Both schooling and local enhancement are examples of self-organization where individual behavior results in a complex and aggregated spatial pattern on larger scales. Moreover, both phenomena are thought to produce positive density dependence. For schooling, there is a minimum number of individuals needed to create an effective school, with the protection from predation through dilution increasing with increasing group size (Courchamp et al. 1999). For local enhancement, more seabirds will be more effective in locating prey patches, and individual foraging success will therefore 
increase with increasing seabird density (see Fig. 3, Grünbaum \& Veit 2003). Positive density-dependent regulation linked to aggregative behavior will generate highly unstable spatial interactions between predators and prey (Abrams 2007). In light of this destabilizing factor, how is a long-lasting interaction between schooling prey and their predators possible? The answer to this question is probably that schooling and local enhancement are local processes operating on small spatial and temporal scales. Thus, although predation might have devastating effects on local aggregations of prey (e.g. Temming et al. 2007) and elusive prey might have strong negative impact on the foraging success of seabirds locally (e.g. Suryan et al. 2002), the effects may be leveled off on larger spatial scales. Indeed, it can be argued that spatial constraints that tend to stabilize the interaction (e.g. physical oceano- graphy) generally operate on larger spatial scales (Weimerskirch 2007) while aggregative behavior linked with positive density dependence are mainly prevalent on smaller scales.

\section{Density-dependent migratory waves}

Although studies on self-organization have generally focused on phenomena occurring at relatively small spatial scales, simple behavioral mechanisms might also be responsible for spatial patterns generated at much larger scales. One behavioral mechanism that can produce a large-scale spatial pattern in the distribution of organisms is ARS (Wilson \& Richards 2000, Fauchald et al. 2006). According to the ARS theory, an individual should increase its turning rate and
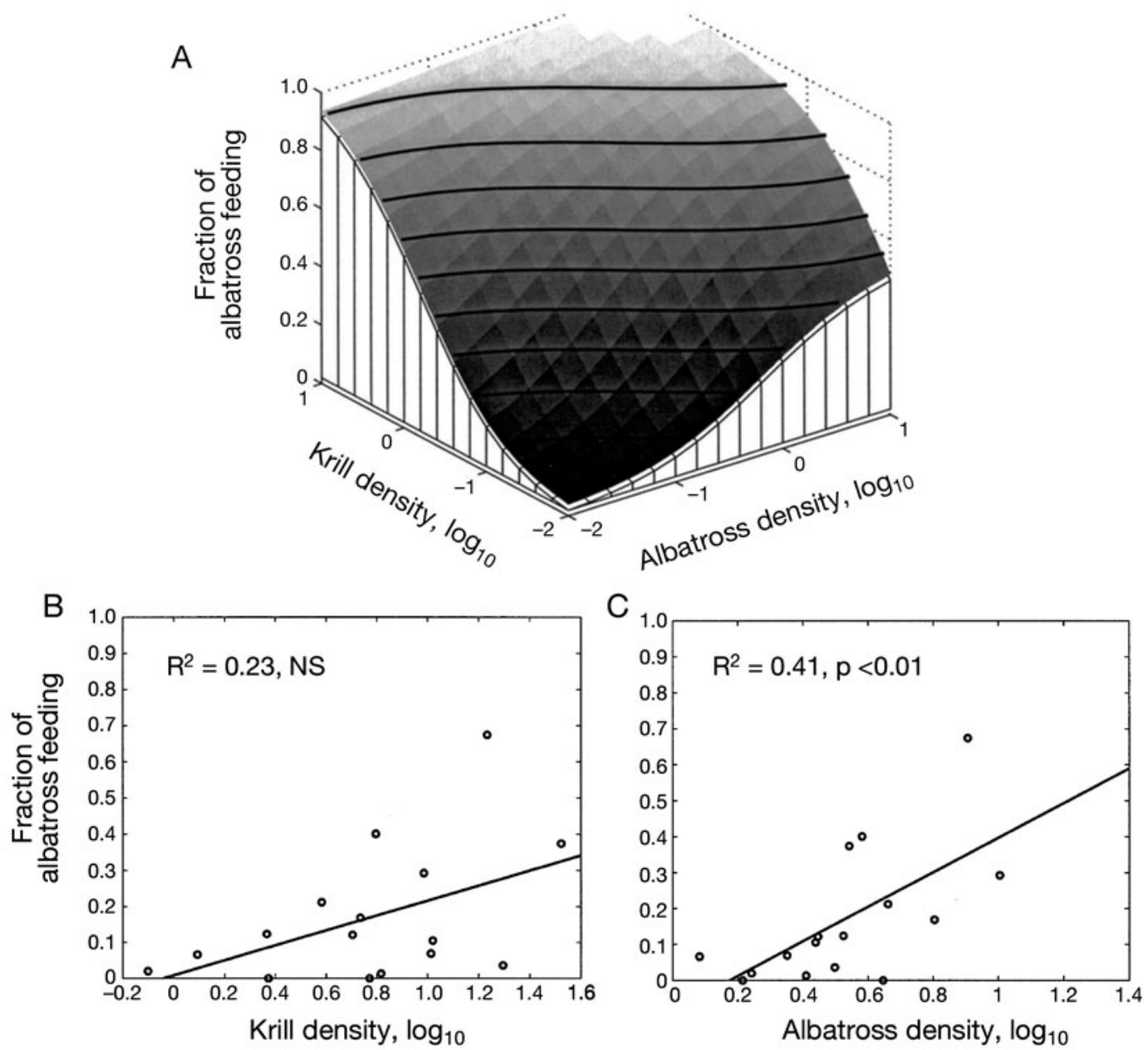

Fig. 3. Positive density dependence through local enhancement in albatross feeding flocks. Foraging success is measured as the fraction of albatrosses feeding. (A) Predictions from a foraging model of local enhancement that assumes that the detectability of foraging albatrosses is 100x the detectability of krill swarms. The model predicts that foraging success should increase with increased density of krill and albatrosses. (B, C) Empirical relationships between krill density, albatross density and albatross foraging success along 16 transects of 50 nautical miles, close to South Georgia (summer 1986). (From Grünbaum \& Veit 2003, used with permission) 
reduce its speed in response to an elevated reward from a resource. This behavior will concentrate the search activity of a forager to profitable areas with high resource levels (Kareiva \& Odell 1987). Wilson \& Richards (2000) showed that this simple foraging principle might result in resource-mediated, densitydependent group formations. In their model, dense aggregations of foragers that swept through the habitat were formed under high density. For example, a school of feeding fish might create a spatial gradient in the density of prey, with high density in front and reduced density behind the school. According to the ARS theory, schools lagging behind such resource gradients will speed up while schools ahead of the gradient will slow down. As a result, schools will automatically congregate, and, under high density, will generate a migratory wave that sweeps across the ocean and effectively reduce the density of prey to very low levels. This phenomenon has been termed density-dependent migratory wave (DDMW), and was suggested by Fauchald et al. (2006) to be responsible for the increased aggregation and spatial displacement of capelin during their feeding migration in years of high capelin abundance in the Barents Sea. In a DDMW, simple collective individual behavior is responsible for the formation of a large-scale spatial pattern with potentially strong perturbing effects on the ecosystem.

\section{Nested area-restricted search}

It has been suggested that seabirds use ARS to track the scale-dependent and patchy spatial distribution of prey (Fauchald 1999, Veit 1999, Pinaud \& Weimerskirch 2005). However, when prey is distributed within nested patch hierarchies, a free-ranging predator should adopt some form of nested ARS (Fig. 4; Fauchald 1999). For example, in a study of murres foraging on capelin during the capelin spawning migration in the Barents Sea, Fauchald et al. (2000) found 3 nested levels of patchiness. They suggested that murres used nested ARS to track the migrating capelin. ARS in its simplest form is a strategy where a predator changes its search pattern according to the encounter rate with prey items. In a nested patch system, it is essential that the scale of the search pattern is tuned to the scale of the level in the hierarchy where the predator is situated (cf. Fig. 4 in Fauchald \& Tveraa 2006). Accordingly, the movement pattern of predators will mimic the spatial pattern of the prey. Moreover, depending on their search efficiency, the spatial distribution of predators will resemble the spatial distribution of the prey (Fauchald et al. 2000).

Recently, several telemetry studies have found that the foraging pattern of seabirds conforms with a nested

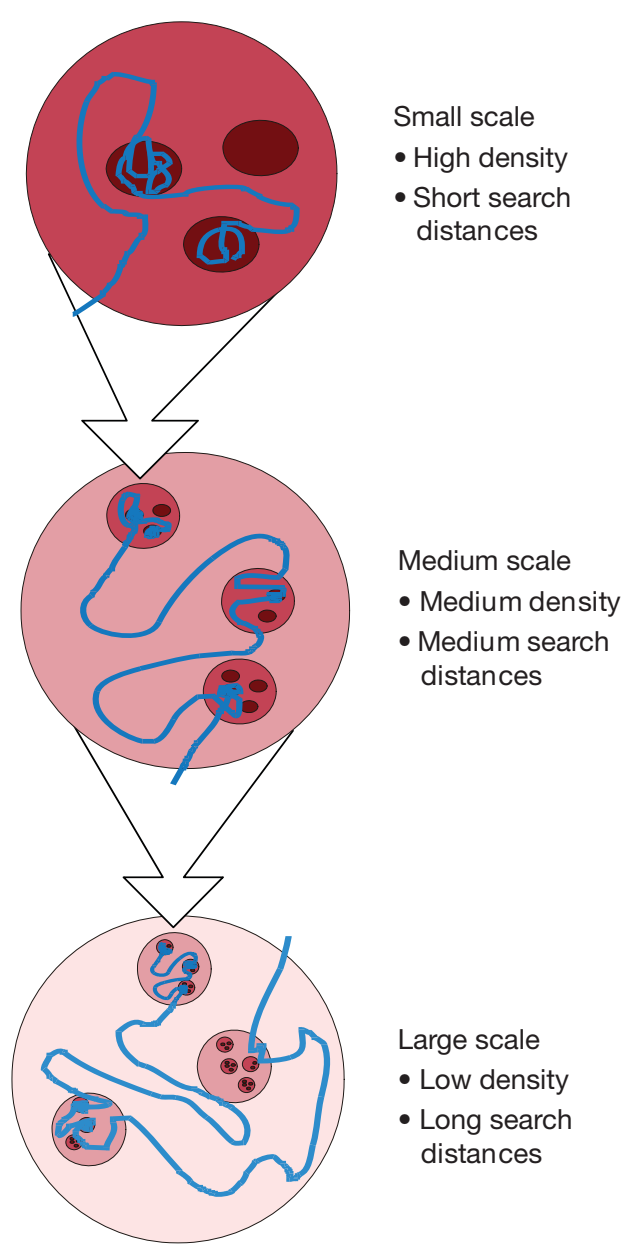

Fig. 4. Hierarchical patch system with high-density smallscale patches (dark red) nested within low-density large-scale patches (light red). Blue line is the search pattern of a forager using a nested area-restricted search

ARS (Fritz et al. 2003, Pinaud \& Weimerskirch 2005, 2007, Fauchald \& Tveraa 2006). However, few studies have tested whether ARS in seabirds is actually triggered by encounters with prey. Weimerskirch et al. (2007) demonstrated that wandering albatrosses Diomedea exulans did not show any strong ARS response to prey capture at large scales. The albatrosses only showed increased sinuosity in their movement pattern after prey encounters at small scales. They suggested that the wandering albatrosses used other cues to modify their movement pattern at large scales. Indeed, when prey density is low, encounter rate might be a very sparse source of information. Other important sources of information can come from e.g. learning and recent spatial experience (Irons 1998, Davoren et al. 2003), olfactory cues (Nevitt et al. 1995, 2008), and the foraging activity of other animals (i.e. local enhancement) (Grünbaum \& Veit 2003). 
Compared to a random strategy, nested ARS is a highly effective search strategy (Fauchald 1999). The search efficiency depends on how fast information is gathered relative to how fast the system changes. How fast information is gathered depends on 2 factors (Fauchald 1999). First, if the encounter rate between predator and prey is high, then the information flow is also high. Thus, the ability to track the system should increase for increased prey abundance. Second, a big difference in prey density between different levels in the hierarchy increases the predator's ability to discriminate between them, hence increasing the predator's ability to track the system. According to the DDMW mechanism, increased abundance of schooling prey will result in increased aggregation. Presumably within certain limits, both increased prey aggregation and prey abundance should increase the predator's ability to track the system. This was actually observed in the interaction between capelin and murres in the Barents Sea (Fauchald \& Erikstad 2002). In years of high capelin abundance, capelin was more aggregated and there was a closer spatial match betweeen capelin and murres compared to years of low capelin abundance. This mechanism would certainly protect the prey population at low density, and would, in contrast to local enhancement and schooling, tend to stabilize the predator-prey interaction.

\section{CONCLUSIONS}

Thirty years of studies have shown that the spatial distribution of seabirds and their prey seldom fits the simple habitat matching rule predicted by the Ideal Free Distribution theory. The spatial match between seabirds and prey has often been found to be much lower than expected. One reason for the discrepancy between theory and empirical findings is the assumption of a nonresponsive prey. To understand the spatial interaction between predator and prey, it is essential to realize that this is a 2 -way interaction including responses and counter-responses in a behavioral game. Thus, the expectation of a strong spatial correlation has been exaggerated in many cases. How predators and prey are spatially constrained and how such constraints affect the spatial interaction are essential for the outcome of the spatial race. Such constraints include the spatial distribution of resources, interspecific competition, the location of spawning and breeding areas, and limitations with respect to diving depth. The spatial pattern of seabirds and prey is often found to be more aggregated and elusive than could be expected from the equilibriums predicted by game theoretic models. The major reason for this is the formation of spatial patterns through collective self- organizing behavior. Such behavior includes schooling, local enhancement and area-restricted search. Local enhancement and schooling are aggregative behaviors that cause positive density dependence at local scales. This kind of self-organizing behavior will therefore have a strong destabilizing effect on the predator-prey interaction locally. However, spatial constraints on predators and prey will tend to stabilize the interaction at larger scales. Thus, a large spatial extent is of vital importance in stabilizing predatorprey interactions in the pelagic ecosystem.

Acknowledgements. I thank J. Gonzalez-Solis for inviting me to write this paper, T. Tveraa for numerous discussions, and V. H. Hausner for helpful comments on earlier versions. Three anonymous reviewers gave valuable comments that greatly improved the manuscript. This study was financed by the Norwegian Research Council.

\section{LITERATURE CITED}

Abrahams MV, Dill LM (1989) A determination of the energetic equivalence of the risk of predation. Ecology 70 : 999-1007

Abrams RW (1985) Environmental determinants of pelagic seabird distribution in the African sector of the Southern Ocean. J Biogeogr 12:473-492

> Abrams PA (2007) Habitat choice in predator-prey systems: spatial instability due to interacting adaptive movements. Am Nat 169:581-594

Ainley DG, Ribic CA, Fraser WR (1992) Does prey preference affect habitat choice in Antarctic seabirds? Mar Ecol Prog Ser 90:207-221

> Ainley DG, Ford RG, Brown ED, Suryan RM, Irons DB (2003) Prey resources, competition, and geographic structure of kittiwake colonies in Prince William Sound. Ecology 84: 709-723

Ainley DG, Ribic CA, Ballard G, Heath S and others (2004) Geographic structure of Adelie penguin populations: overlap in colony-specific foraging areas. Ecol Monogr 74: $159-178$

Alonzo SH (2002) State-dependent habitat selection games between predators and prey: the importance of behavioural interactions and expected lifetime reproductive success. Evol Ecol Res 4:759-778

Alonzo SH, Switzer PV, Mangel M (2003) Ecological games in space and time: the distribution and abundance of Antarctic krill and penguins. Ecology 84:1598-1607

Ashmole NP (1963) The regulation of numbers of tropical oceanic birds. Ibis 103:458-473

Axelsen BE, Nøttestad L, Ferno A, Johannessen A, Misund OA (2000) 'Await' in the pelagic: dynamic trade-off between reproduction and survival within a herring school splitting vertically during spawning. Mar Ecol Prog Ser 205:259-269

Ballance LT, Pitman RL, Reilly SB (1997) Seabird community structure along a productivity gradient: importance of competition and energetic constraint. Ecology 78: 1502-1518

Becker BH, Beissinger SR (2003) Scale-dependent habitat selection by a nearshore seabird, the marbled murrelet, in a highly dynamic upwelling system. Mar Ecol Prog Ser 256:243-255

Bernstein C, Kacelnik A, Krebs JR (1988) Individual decisions 
and the distribution of predators in a patchy environment. J Anim Ecol 57:1007-1026

Cairns DK, Schneider DC (1990) Hot spots in cold water: feeding habitat selection by thick-billed murres. J Avian Biol 14:52-60

Chase JM, Leibold MA (2003) Ecological niches: linking classical and contemporary approaches. University of Chicago Press, Chicago

Coulson JC (2002) Colonial breeding in seabirds. In: Schreiber EA, Burger J (eds) Biology of marine birds. CRS Press, Boca Raton, FL, p 87-113

- Courchamp F, Clutton-Brock T, Grenfell B (1999) Inverse density dependence and the Allee effect. Trends Ecol Evol 14:405-410

Coyle KO, Cooney RT (1993) Water column sound scattering and hydrography around the Pribilof Islands, Bering Sea. Cont Shelf Res 13:803-827

Davoren GK, Montevecchi WA, Anderson JT (2003) Distributional patterns of a marine bird and its prey: habitat selection based on prey and conspecific behaviour. Mar Ecol Prog Ser 256:229-242

Decker MB, Hunt GL (1996) Foraging by murres (Uria spp.) at tidal fronts surrounding the Pribilof Islands, Alaska, USA. Mar Ecol Prog Ser 139:1-10

Durazo R, Harrison NM, Hill AE (1998) Seabird observations at a tidal mixing front in the Irish Sea. Estuar Coast Shelf Sci 47:153-164

Erikstad KE, Moum T, Vader W (1990) Correlations between pelagic distribution of common and Brünnich's guillemots and their prey in the Barents Sea. In: Brekke A (ed) Polar Res 8:77-87

Fauchald P (1999) Foraging in a hierarchical patch system. Am Nat 153:603-613

Fauchald P, Erikstad KE (2002) Scale-dependent predatorprey interactions: the aggregative response of seabirds to prey under variable prey abundance and patchiness. Mar Ecol Prog Ser 231:279-291

Fauchald P, Tveraa T (2006) Hierarchical patch dynamics and animal movement pattern. Oecologia 149:383-395

Fauchald P, Erikstad KE, Skarsfjord H (2000) Scale-dependent predator-prey interactions: the hierarchical spatial distribution of seabirds and prey. Ecology 81:773-783

Fauchald P, Mauritzen M, Gjøsæter H (2006) Densitydependent migratory waves in the marine pelagic ecosystem. Ecology 87:2915-2924

Fiksen O, Eliassen S, Titelman J (2005) Multiple predators in the pelagic: modelling behavioural cascades. J Anim Ecol 74:423-429

Forero MG, Tella JL, Hobson KA, Bertellotti M, Blanco G (2002) Conspecific food competition explains variability in colony size: a test in Magellanic penguins. Ecology 83: 3466-3475

Fretwell SD, Lucas HL Jr (1969) On territorial behavior and other factors influencing habitat distribution in birds. Acta Biotheor 19:16-36

Fritz H, Said S, Weimerskirch H (2003) Scale-dependent hierarchical adjustments of movement patterns in a longrange foraging seabird. Proc R Soc Lond B Biol Sci 270: $1143-1148$

Gjøsæter H (1998) The population biology and exploitation of capelin (Mallotus villosus) in the Barents Sea. Sarsia 83: 453-496

Grémillet D, Dell'Omo G, Ryan PG, Peters G, Ropert-Coudert Y, Weeks SJ (2004) Offshore diplomacy, or how seabirds mitigate intraspecific competition: a case study based on GPS tracking of Cape gannets from neighbouring colonies. Mar Ecol Prog Ser 268:265-279
Grünbaum D, Veit RR (2003) Black-browed albatrosses foraging on Antarctic krill: density-dependence through local enhancement? Ecology 84:3265-3275

Hamilton WD (1971) Geometry for the selfish herd. J Theor Biol 31:295-311

Harrison NM, Whitehouse MJ, Heinemann D, Prince PA, Hunt GL, Veit RR (1991) Observations of multispecies seabird flocks around South Georgia. Auk 108:801-810

Harrison NM, Webb A, Leaper GM (1994) Patterns in seabird distribution west of Scotland. Aquat Conserv: Mar Freshwat Ecosyst 4:21-30

Haury LR, McGowan JA, Wiebe PH (1978) Patterns and processes in the time-space scales of plankton distributions. In: Steele JH (ed) Spatial pattern in plankton communities. Plenum Press, New York, p 277-327

> Hay RB (1992) The oceanic habitats of seabirds: their zonal distribution off Vancouver Island, British Columbia, Canada. J Biogeogr 19:67-85

Heinemann D, Hunt G, Everson I (1989) Relationships between the distributions of marine avian predators and their prey Euphasia superba in Bransfield Strait and Southern Drake Passage, Antarctica. Mar Ecol Prog Ser 58:3-16

Hoffman W, Heinemann D, Wiens JA (1981) The ecology of seabird feeding flocks in Alaska. Auk 98:437-456

Hugie DM, Dill LM (1994) Fish and game: a game-theoretic approach to habitat selection by predators and prey. J Fish Biol 45:151-169

Hunt GL Jr (1990) The pelagic distribution of marine birds in a heterogeneous environment. Polar Res 8:43-54

- Hunt GL, Harrison NM (1990) Foraging habitat and prey taken by least auklets at King Island, Alaska. Mar Ecol Prog Ser 65:141-150

Hunt GL Jr, Schneider DC (1987) Scale-dependent processes in the physical and biological environment of marine birds. In: Croxall JP (ed) Seabirds: feeding biology and role in marine ecosystems. Cambridge University Press, Cambridge

Hunt GL Jr, Harrison NM, Cooney RT (1990) The influence of hydrographic structure and prey abundance on foraging of least auklets. J Avian Biol 14:7-22

$>$ Hunt GL, Heinemann D, Everson I (1992) Distributions and predator-prey interactions of macaroni penguins, Antarctic fur seals, and Antarctic krill near Bird Island, South Georgia. Mar Ecol Prog Ser 86:15-30

$>$ Hunt GL, Coyle KO, Hoffman S, Decker MB, Flint EN (1996) Foraging ecology of short-tailed shearwaters near the Pribilof Islands, Bering Sea. Mar Ecol Prog Ser 141:1-11

Hunt GL, Mehlum F, Russell RW, Irons D, Decker MB, Becker PH (1999) Physical processes, prey abundance, and the foraging ecology of seabirds. In: Adams NJ, Slotow RH (eds) Proc 22nd Int Ornithol Congr. Birdlife South Africa, Durban, p 2040-2046

Hyrenbach KD, Veit RR, Weimerskirch H, Metzl N, Hunt GL (2007) Community structure across a large-scale ocean productivity gradient: marine bird assemblages of the southern Indian Ocean. Deep-Sea Res I 54:1129-1145

Irons DB (1998) Foraging area fidelity of individual seabirds in relation to tidal cycles and flock feeding. Ecology 79:647-655

Iwasa Y (1982) Vertical migration of zooplankton: a game between predator and prey. Am Nat 120:171-180

Johnsen E, Skaret G (2008) Adaptive mass formations in fish shoals founded in conflicting motivation. Mar Ecol Prog Ser 358:295-300

Kareiva P, Odell G (1987) Swarms of predators exhibit 'preytaxis' if individual predators use area-restricted search. Am Nat 130:233-270 
Kinder TH, Hunt GL Jr, Schneider DC, Schumacher JD (1983) Correlation between seabirds and oceanic fronts around the Pribilof Islands, Alaska. Estuar Coast Shelf Sci 16:309-319

Kotliar NB, Wiens JA (1990) Multiple scales of patchiness and patch structure: a hierarchical framework for the study of heterogeneity. Oikos 59:253-260

Levin SA (1992) The problem of pattern and scale in ecology. Ecology 73:1943-1967

Lewis S, Sherratt TN, Hamer KC, Wanless S (2001) Evidence of intraspecific competition for food in a pelagic seabird. Nature 412:816-819

Lima SL (2002) Putting predators back into behavioral predator-prey interactions. Trends Ecol Evol 17:70-75

Lima SL, Dill LM (1990) Behavioral decisions made under the risk of predation: a review and prospectus. Can J Zool 68: 619-640

Logerwell EA, Hargreaves NB (1996) The distribution of sea birds relative to their fish prey off Vancouver Island: opposing results at large and small spatial scales. Fish Oceanogr 5:163-175

Mehlum F, Hunt GL, Klusek Z, Decker MB, Nordlund N (1996) The importance of prey aggregations to the distribution of Brünnich's guillemots in Storfjorden, Svalbard. Polar Biol 16:537-547

Millinski M, Parker GA (1991) Competition for resources. In: Krebs JR, Davies NB (eds) Behavioural ecology. An evolutionary approach. Blackwell Scientific Publications, Oxford, p 137-168

Mills KL (1998) Multispecies seabird feeding flocks in the Galapagos Islands. Condor 100:277-285

> Mitchell WA, Lima SL (2002) Predator-prey shell games: large-scale movement and its implications for decision making by prey. Oikos 99:249-259

Murphy EJ, Morris DJ, Watkins JL, Priddle J (1988) Scales of interactions between Antarctic krill and the environment. In: Sahrhage D (ed) Antarctic Ocean and resources variability. Springer, Berlin, p 120-130

> Nevitt GA, Veit RR, Kareiva P (1995) Dimethyl sulfide as a foraging cue for Antarctic procellariiform seabirds. Nature 376:680-682

Nevitt GA, Losekoot M, Weimerskirch H (2008) Evidence for olfactory search in wandering albatross Diomedea exulans. Proc Natl Acad Sci USA 105:4576-4581

Nøttestad L, Aksland M, Beltestad A, Ferno A, Johannessen A, Misund OA (1996) Schooling dynamics of Norwegian spring spawning herring Clupea harengus L. in a coastal spawning area. Sarsia 80:277-284

Obst BS (1985) Densities of Antarctic seabirds at sea and the presence of the krill Euphausia superba. Auk 102:540-549

Orians GH, Pearson NE (1979) On the theory of central place foraging. In: Horn DJ, Mitchell RD, Stairs GR (eds) Analysis of ecological systems. Ohio State University Press, Columbus, p 154-177

Pakhomov EA, McQuaid CD (1996) Distribution of surface zooplankton and seabirds across the Southern Ocean. Polar Biol 16:271-286

Parrish JK, Edelstein-Keshet L (1999) Complexity, pattern, and evolutionary trade-offs in animal aggregation. Science 284:99-101

Partridge BL (1982) The structure and function of fish schools. Sci Am 246:114-123

Piatt JF (1990) The aggregative response of common murres and Atlantic puffins to schools of capelin. J Avian Biol 14: $36-51$

Piatt JF, Wetzel J, Bell K, DeGange AR and others (2006) Predictable hotspots and foraging habitat of the endangered short-tailed albatross Phoebastria albatrus in the North Pacific: implications for conservation. Deep-Sea Res II 53: 387-398

> Pinaud D, Weimerskirch H (2005) Scale-dependent habitat use in a long-ranging central place predator. J Anim Ecol 74:852-863

> Pinaud D, Weimerskirch H (2007) At-sea distribution and scale-dependent foraging behaviour of petrels and albatrosses: a comparative study. J Anim Ecol 76:9-19

Ripple WJ, Larsen EJ, Renkin RA, Smith DW (2001) Trophic cascades among wolves, elk and aspen on Yellowstone National Park's northern range. Biol Conserv 102:227-234

Rose GA, Leggett WC (1990) The importance of scale to predator-prey spatial correlations: an example of Atlantic fishes. Ecology 71:33-43

Ryan PG, Cooper J (1989) The distribution and abundance of aerial seabirds in relation to Antarctic krill in the Prydz Bay region, Antarctica, during late summer. Polar Biol 10: 199-209

Safina C, Burger J (1985) Common tern foraging: seasonal trends in prey fish densities and competition with bluefish. Ecology 66:1457-1463

Schneider DC, Harrison NM, Hunt GL Jr (1990) Seabird diet at a front near the Pribilof Islands, Alaska. J Avian Biol 14: $61-66$

Schwinning S, Rosenzweig ML (1990) Periodic oscillations in an ideal free predator-prey distribution. Oikos 59:85-91

Shaw E (1978) Schooling in fishes. Am Sci 66:166-175

> Sih A (1984) The behavioral response race between predator and prey. Am Nat 123:143-150

Sih A (1998) Game theory and predator-prey response races. In: Dugatkin JA, Reeves HK (eds) Game theory and animal behavior. Oxford University Press, New York, p 221-238

Sih A (2005) Predator-prey space use as an emergent outcome of a behavioral response race. In: Barbosa P, Castellanos I (eds) Ecology of predator-prey interactions. Oxford University Press, New York, p 240-255

Silverman ED, Veit RR, Nevitt GA (2004) Nearest neighbors as foraging cues: information transfer in a patchy environment. Mar Ecol Prog Ser 277:25-35

Skov H, Durinck J (2000) Seabird distribution in relation to hydrography in the Skagerrak. Cont Shelf Res 20:169-187

Skov H, Durinck J, Andell P (2000) Associations between wintering avian predators and schooling fish in the Skagerrak-Kattegat suggest reliance on predictable aggregations of herring Clupea harengus. J Avian Biol 31: 135-143

Stephens DW, Krebs JR (1986) Foraging theory. Princeton University Press, Princeton, NJ

Sumpter DJT (2006) The principles of collective animal behaviour. Philos Trans R Soc Lond B 361:5-22

Suryan RM, Irons DB, Kaufman M, Benson J, Jodice PGR, Roby DD, Brown ED (2002) Short-term fluctuations in forage fish availability and the effect on prey selection and brood-rearing in the black-legged kittiwake Rissa tridactyla. Mar Ecol Prog Ser 236:273-287

Sutherland WJ (1983) Aggregation and the 'ideal free' distribution. J Anim Ecol 52:821-828

Swartzman G, Hunt G (2000) Spatial association between murres (Uria spp.), puffins (Fratercula spp.) and fish shoals near Pribilof Islands, Alaska. Mar Ecol Prog Ser 206: 297-309

- Temming A, Floeter J, Ehrich S (2007) Predation hot spots: large-scale impact of local aggregations. Ecosystems 10: 865-876

van Baalen M, Sabelis MW (1993) Coevolution of patch selec- 
tion strategies of predator and prey and the consequences for ecological stability. Am Nat 142:646-670

Veit RR (1999) Behavioural responses by foraging petrels to swarms of Antarctic krill Euphausia superba. Ardea 87: $41-50$

Veit RR, Silverman ED, Everson I (1993) Aggregation patterns of pelagic predators and their principal prey, Antarctic krill, near South Georgia. J Anim Ecol 62:551-564

> Vilchis LI, Ballance LT, Fiedler PC (2006) Pelagic habitat of seabirds in the eastern tropical Pacific: effects of foraging ecology on habitat selection. Mar Ecol Prog Ser 315: 279-292

Wahl TR, Ainley DG, Benedict AH, Degange AR (1989) Associations between seabirds and water masses in the northern Pacific Ocean in summer. Mar Biol 103:1-11

Weimerskirch H (2007) Are seabirds foraging for unpredictable resources? Deep-Sea Res II 54:211-223

Weimerskirch $\mathrm{H}$, Cherel Y, Cuenot-Chaillet F, Ridoux V

Editorial responsibility: Scott Shaffer,

Santa Cruz, California, USA
(1997) Alternative foraging strategies and resource allocation by male and female wandering albatrosses. Ecology 78:2051-2063

Weimerskirch H, Pinaud D, Pawlowski F, Bost CA (2007) Does prey capture induce area-restricted search? A fine-scale study using GPS in a marine predator, the wandering albatross. Am Nat 170:734-743

Willis J (2007) Could whales have maintained a high abundance of krill? Evol Ecol Res 9:651-662

Wilson WG, Richards SA (2000) Consuming and grouping: resource-mediated animal aggregation. Ecol Lett 3: $175-180$

Woodby DA (1984) The April distribution of murres and prey patches in the southeastern Bering Sea. Limnol Oceanogr 29:181-188

Wu J, Loucks OL (1995) From balance of nature to hierarchical patch dynamics: a paradigm shift in ecology. Q Rev Biol 70:439-466

Submitted: May 26, 2008; Accepted: November 4, 2008 Proofs received from author(s): February 17, 2009 